\title{
Odontogenic effects of two calcium silicate-based biomaterials in human dental pulp cells
}

\author{
Emel Olga Önay ${ }^{1, A-F}$, Erkan Yurtcu ${ }^{2, B-D}$, Yunus Kasim Terziं ${ }^{3, B-D}$, Mete Üngör ${ }^{1, E}$, Yener Oguz ${ }^{4, B}$, Feride Iffet Şahin ${ }^{3, E}$ \\ ${ }^{1}$ Department of Endodontics, School of Dentistry, Baskent University, Ankara, Turkey \\ 2 Department of Medical Biology, School of Medicine, Baskent University, Ankara, Turkey \\ ${ }^{3}$ Department of Medical Genetics, School of Medicine, Baskent University, Ankara, Turkey \\ ${ }^{4}$ Department of Oral Surgery and Implantology, Private practice (Drs Nicolas \& Asp), Dubai, United Arab Emirates \\ A - research concept and design; $\mathrm{B}$ - collection and/or assembly of data; $\mathrm{C}$ - data analysis and interpretation; \\ $D$ - writing the article; $E$ - critical revision of the article; $F$ - final approval of the article
}

\author{
Address for correspondence \\ Emel Olga Önay \\ E-mail: eonay@baskent.edu.tr

\section{Funding sources} \\ None declared

\section{Conflict of interest} \\ None declared

\section{Acknowledgements} \\ This study was supported by Research Grant \\ No. D-KA13/06 from Baskent University Research \\ Fund. The authors are grateful to Dr. Mustafa Agah \\ Tekindal for providing assistance with \\ the statistics.
}

Received on February 25, 2017

Reviewed on April 18, 2017

Accepted on May 30, 2017

\begin{abstract}
Background. The goal of treating exposed pulp with an appropriate pulp capping material is to promote the dentinogenic potential of the pulpal cells. There have been recent attempts to develop more effective pulp-capping materials.

Objectives. The aim of this study was to evaluate the effect of newly developed calcium silicate-based material on odontogenic differentiation of primary human dental pulp cells (HDPCS), in comparison with a contemporary calcium silicate-based material.

Material and methods. Human dental pulp cells isolated from dental pulps were cultured in standard culture conditions in Dulbecco's Modified Eagle's Medium (DMEM) and then the effects of Micro-Mega mineral trioxide aggregate (MM-MTA) (Micro-Mega, Besançon, France) and ProRoot MTA (MTA) (Dentsply Sirona, Tulsa, USA) (positive control) were evaluated on HDPCs at 1,7 and 14 days. Untreated cells were used as a negative control. Odontoblastic differentiation was assessed by alkaline phosphatase (ALP) activity. Runtrelated transcription factor 2 (RUNX2), alkaline phosphatase liver/bone/kidney (ALPL), bone morphogenetic protein 2 (BMP2), dentin sialophosphoprotein (DSPP), and Distal-less homeobox 3 (DLX3), as odontoblastic/ osteoblastic expression markers, were evaluated by semi-quantitative real-time polymerase chain reaction (RT-PCR) analysis. Calcium levels of culture media were also determined.

Results. The MM-MTA group significantly increased the expression of BMP2 compared with that of the MTA group at 3 different time periods $(p<0.05)$. The up-regulation of ALPL between day 1 and 14 and the up-regulation of DSPP between day 7 and 14 were significant in both groups $(p<0.05)$. Micro-Mega MTA and MTA exhibited similar messenger RNA (mRNA) expression levels of ALPL, DSPP, RUNXZ, DLX3, and ALP activities, as well as calcium levels.
\end{abstract}

Conclusions. Based on the cell responses observed in this study, MM-MTA might be used efficiently in dental pulp therapy as a potential alternative to MTA.

Key words: alkaline phosphatase, calcium silicate, dentinogenesis, mineral trioxide aggregate, transcription factors

DOI

10.17219/acem/74197

Copyright

Copyright by Author(s)

This is an article distributed under the terms of the

Creative Commons Attribution Non-Commercial License

(http://creativecommons.org/licenses/by-nc-nd/4.0/) 


\section{Introduction}

Mineral trioxide aggregate (MTA) was introduced in the early 1990s and has been the material of choice for endodontic therapies due to its high mineralization capacity and relatively few inflammatory reactions in clinical use., ${ }^{1,2}$ A number of in vivo and in vitro studies concerning cell and tissue interactions with MTA have shown its favorable biological characteristics. Some in vivo studies showed that MTA allowed cemental regeneration over the root-end filling when used in dogs and monkeys, whereas in vitro studies reported osteoblasts, periodontal ligament cells, bone marrow stromal cells, and dental pulp cells attached to MTA, inducing proliferation. ${ }^{3-12}$ Moreover, the placement of MTA on pulp tissue leads to the proliferation, migration and differentiation of odontoblast-like cells, which produce a collagen matrix. ${ }^{1}$

Despite many positive characteristics, MTA has a couple of disadvantages, such as its extended setting time, difficulty in handling due to its sandy consistency and high porosity, poor dispersion, and high cost. ${ }^{13,14}$

After the development of MTA, many types of endodontic cements were developed, with Micro-Mega MTA (MM-MTA; Micro-Mega, Besançon, France) being one of those materials. It has a similar content as MTA, which is composed of tricalcium silicate, dicalcium silicate, tricalcium aluminate, calcium sulfate dehydrate, bismuth oxide, magnesium oxide, calcium carbonate $\left(\mathrm{CaCO}_{3}\right)$, and chloride accelerator. ${ }^{15,16}$ The shorter setting time of MM-MTA is thought to be a result of the addition of $\mathrm{CaCO}_{3}$ and chloride accelerator to the formula. ${ }^{16}$ The material has also shown to be safe with respect to acceptable levels of arsenic, lead and metal oxides. ${ }^{15}$ Additionally, the evaluation of different physical properties of the material that mainly focused on the radiopacity and push-out bond strength has yielded favorable results. ${ }^{17,18}$ The MM-MTA is pre-dosed and the activated capsule is mechanically mixed, thus ensuring correct proportioning and homogenous mixing.

A number of studies have reported that the dentin bridge formation ability, biocompatibility, odontogenic differentiation, inflammatory response, and angiogenic potential of MM-MTA were all similar to those of MTA. ${ }^{19-21}$ However, the exact mechanism of dentin regeneration/dentinogenesis after exposure to MTA and MM-MTA has not yet been completely explicated. Thus, the aim of this study was to evaluate and compare the biologic effects of newly developed MM-MTA and MTA on odontogenic differentiation of primary human dental pulp cells (HDPCs). The null hypothesis was that MTA and MM-MTA have similar effects in promoting odontogenic differentiation.

\section{Material and methods}

Six human impacted $3^{\text {rd }}$ molars without any pathology extracted for orthodontic and impacted reasons were collected from 6 donors aged 18-25 years with informed consent, under a protocol approved by the Institutional Review Board and Ethics Committee of Baskent University, Ankara, Turkey (Project No. D-KA13/06). All 3 female and 3 male donors were healthy, without any known disease, were not taking any medications, and were non-smokers and non-alcohol consumers. Immediately after extraction, the extracted molars were cut horizontally at $1 \mathrm{~mm}$ below the cementoenamel junction. The carefully extracted pulp tissue was transferred to the laboratory in Dulbecco's Modified Eagle's Medium (DMEM)-F12 (Biochrom AG, Berlin, Germany) containing 1 drop of $1 \%$ streptomycin, neomycin and penicillin mixture (Biological Industries, Kibbutz Beit-Haemek, Israel). Physical dissection of the specimens was carried out by a scalpel. Under sterile conditions, the specimens were enzymatically digested with type I collagenase and dispase (Biochrom AG). After centrifugation at $500 \mathrm{~g}$ for $9 \mathrm{~min}$, the supernatant was removed and the cells were placed in cell-culture medium (DMEM-F12 containing $10 \%$ heat-inactivated fetal bovine serum [FBS]; Biochrom AG), 2\% L-glutamine (Biochrom AG), and $1 \%$ penicillin-streptomycin mixture (Biological Industries). The cells were cultured at $37^{\circ} \mathrm{C}$ in a humidified incubator supplemented with $5 \% \mathrm{CO}_{2}$ (Heraeus, Hanau, Germany). The cell culture medium was changed every 2-3 days and cells were subcultured when confluence reached $80 \%$. Fourth to $7^{\text {th }}$ subculture of cells was used for experimental procedure. Viability of cells was evaluated using the trypan blue exclusion test and up to $95 \%$ viable cells containing cultures were included in the experiments.

\section{Material preparation and application}

Teflon tubes (10 $\mathrm{mm}$ internal diameter, $2 \mathrm{~mm}$ height) were sterilized with ethylene oxide gas. White MTA (ProRoot MTA; Dentsply Sirona, Tulsa, USA, Lot No. 12002493) (positive control) and MM-MTA (Lot No. 7302238) were prepared according to the manufacturer's instructions, put into the tubes and stored in an incubator at $95 \% \pm 5 \%$ relative humidity at $37^{\circ} \mathrm{C}$ for 1 day.

Dental pulp cells and the tubes were incubated in $9 \mathrm{~cm}^{2}$ Petri dishes. To prevent direct contact of materials with cells, the tubes were placed in a permeable transwell inserts with a pore size of $0.4 \mu \mathrm{m}$ (Greiner Bio-One $\mathrm{GmbH}$, Frickenhausen, Germany). At the end of the 1, 7 and 14-day time periods, the cells were harvested for gene expression and alkaline phosphates $(A L P)$ activity, and also cell culture media were collected for calcium levels. Untreated cells were used as a negative control. All cell culture experiments were repeated in triplicate.

\section{Determination of alkaline phosphatase activity}

Intracellular $A L P$ activities were determined according to the manufacturer's protocol by a commercially available colorimetric kit (Abcam, Cambridge, UK). Briefly, the total 
cell number was determined by using a Thoma cell counting chamber (Paul Marienfeld GmbH \& Co. KG, LaudaKönigshofen, Germany) and subsequently $1 \times 10^{5}$ cells were used. Cells washed in phosphate buffered saline (PBS) were homogenized in an assay buffer and para-nitrophenyl phosphate (pNPP) solution was added on cells in a 96-well microplate. After $60 \mathrm{~min}$ of incubation at room temperature under dark conditions, the stop solution was added. Optical densities were measured at $405 \mathrm{~nm}$ in a microplate spectrophotometer (Epoch; BioTek, Swindon, UK). Data analyses were carried out according to the manufacturer's instruction and $A L P$ activity was expressed as $\mathrm{U} / \mathrm{mL}$.

\section{Determination of calcium levels}

Calcium levels were determined according to the manufacturer's protocol by a commercially available colorimetric kit (Abcam). Then, a chromogenic reagent and an assay buffer were added on $20 \mu \mathrm{L}$ of culture medium in a 96-well microplate. After incubating for 5-10 $\mathrm{min}$ at room temperature under dark conditions, optical densities were measured at $575 \mathrm{~nm}$ in a microplate spectrophotometer (Epoch). Optical density of normal medium was used as blank and subtracted from optical density of all samples. Calcium concentrations were calculated according to the manufacturer's instruction and expressed as $\mathrm{mg} / \mathrm{dL}$.

\section{Real-time polymerase chain reaction analysis}

Total RNA was isolated from MTA and MM-MTA applied cells of 6 patients with TriPure isolation reagent according to the manufacturer's instructions (Roche Diagnostics GmbH, Mannheim, Germany). One microgram of total RNA was reverse transcribed using Transcriptor High Fidelity cDNA Synthesis Kit (Roche Diagnostics $\mathrm{GmbH})$. Real-time ready catalog assays, which are short FAM-labeled hydrolysis probes containing locked nucleic acid, were used for real-time polymerase chain reactions (RT-PCR) (Roche Diagnostics GmbH). Expression of runtrelated transcription factor 2 (RUNX2; Assay ID: 113380), alkaline phosphatase liver/bone/kidney ( $A L P L$; Assay ID: 103448), bone morphogenetic protein 2 (BMP2; Assay ID: 104558), dentin sialophosphoprotein (DSPP; Assay ID: 139816), and distal-less homeobox 3 ( $D L X 3$; Assay ID: 140745) were determined using semi-quantitative RT-PCR by Light Cycler 480 II system (Roche Diagnostics GmbH) according to the manufacturer's instructions with a preincubation step at $95^{\circ} \mathrm{C}$ for $10 \mathrm{~min}$, followed by 45 cycles at $95^{\circ} \mathrm{C}$ for $10 \mathrm{~s}, 60^{\circ} \mathrm{C}$ for $30 \mathrm{~s}$, and $72^{\circ} \mathrm{C}$ for $1 \mathrm{~s}$. Semiquantitative $\mathrm{PCR}$ reactions were run in duplicate, and the relative expression levels of $R U N X 2, A L P L, B M P 2, D S P P$ and $D L X 3$ transcripts' were calculated by the threshold cycle $(\mathrm{Ct})$ and the $2^{\text {-ddCt }}$ method. ${ }^{22}$ Glyceraldehyde 3-phosphate dehydrogenase (GAPDH) (Assay ID: 141139) were used for normalization of the expression data.

\section{Statistical analysis}

The Shapiro-Wilk test was used to assess the normality of distributions of the variables, and Levene's test was used to assess the homogeneity of variances among groups. Parametric test assumptions were not available for some variables. Data transformation methods were applied to these variables and then the analysis was performed. Comparisons of group means were performed with the repeated measures analysis of variance (ANOVA).

Data analyses were performed using the Statistical Package for the Social Sciences, v. 17.0 (SPSS Inc., Chicago, USA). A p-value $<0.05$ was considered statistically significant. The results of statistical analysis were expressed as number of observations ( $\mathrm{n})$, mean \pm standard deviation (mean $\pm \mathrm{SD}$, median and minimum-maximum values $(\min -\max ))$.

\section{Results}

\section{Alkaline phosphatase activity}

Alkaline phosphatase activities levels were increased with MTA and MM-MTA. The most intense ALP activity was exhibited by the MM-MTA group at day 14 . However, there was no significant difference in $A L P$ activity among the negative control, MTA-, and MM-MTA-treated groups for all time periods $(\mathrm{p}>0.05)$ (Fig. 1).

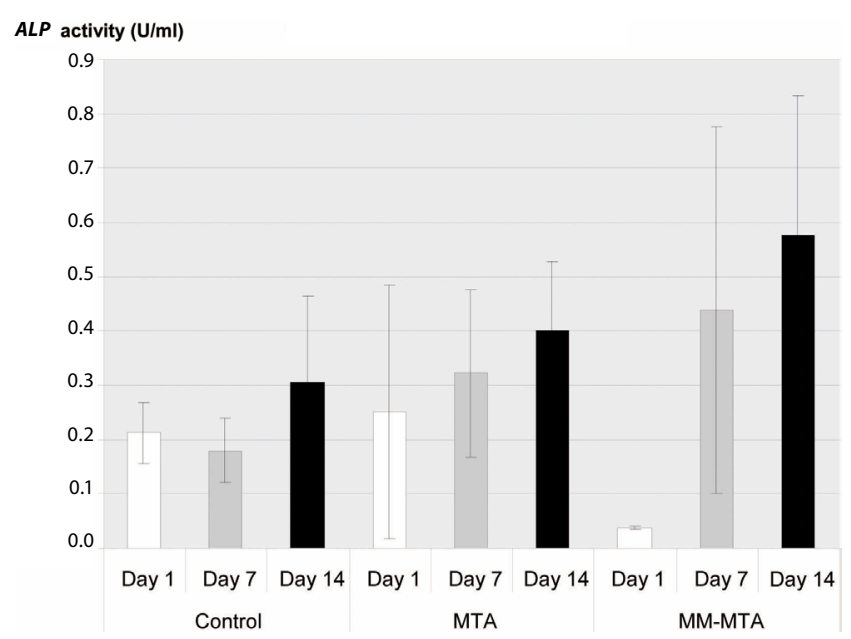

Fig. 1. The effects of MTA and MM-MTA on ALP activity in HDPCs $(p>0.05)$ MTA - mineral trioxide aggregate; MM-MTA - Micro Mega MTA; ALP - alkaline phosphatase; HDPCs - human dental pulp cells.

\section{Calcium levels}

Observation from spectrophotometric analysis at day 7 revealed higher calcium level in HDPCs exposed of MTA and MM-MTA, whereas the calcium levels were not significantly different in negative control, MTA- and MM-MTA-treated groups for all time periods ( $\mathrm{p}>0.05)$ (Fig. 2). 


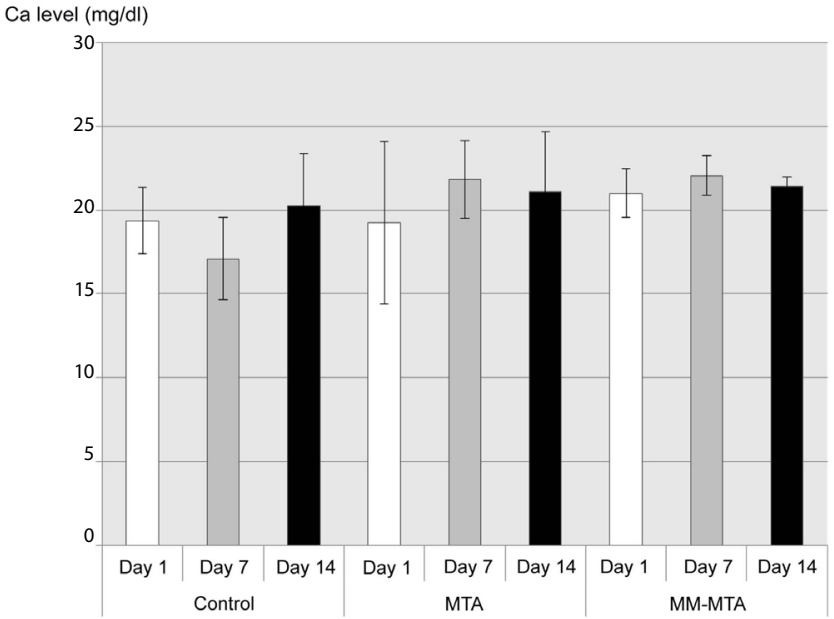

Fig. 2. The calcium levels of MTA and MM-MTA determined by spectrophotometric analysis at different time points (day 1, 7 and 14) ( $p>0.05)$

MTA - mineral trioxide aggregate; MM-MTA - Micro Mega MTA.

\section{Real-time polymerase chain reaction gene expression analysis}

The MM-MTA group significantly increased the expression of $B M P 2$ compared with that of the MTA group at 3 different time periods (day 1, 7 and 14) (p < 0.05) (Fig. 3). The up-regulation of $A L P L$ between day 1 and 14 (Fig. 4), and the up-regulation of DSPP between day 7 and 14 (Fig. 5) were significant in both groups $(\mathrm{p}<0.05)$. A down-regulation of DSPP between day 1 and day 7 , and also between day 1 and day 14, were significant in both groups ( $\mathrm{p}<0.01)$ (Fig. 5). The MM-MTA and MTA groups exhibited similar messenger RNA (mRNA) expression levels of $A L P L$ (Fig. 4), $D S P P$ (Fig. 5), RUNX2 (Fig. 6), and $D L X 3$ (Fig. 7) (p >0.05).

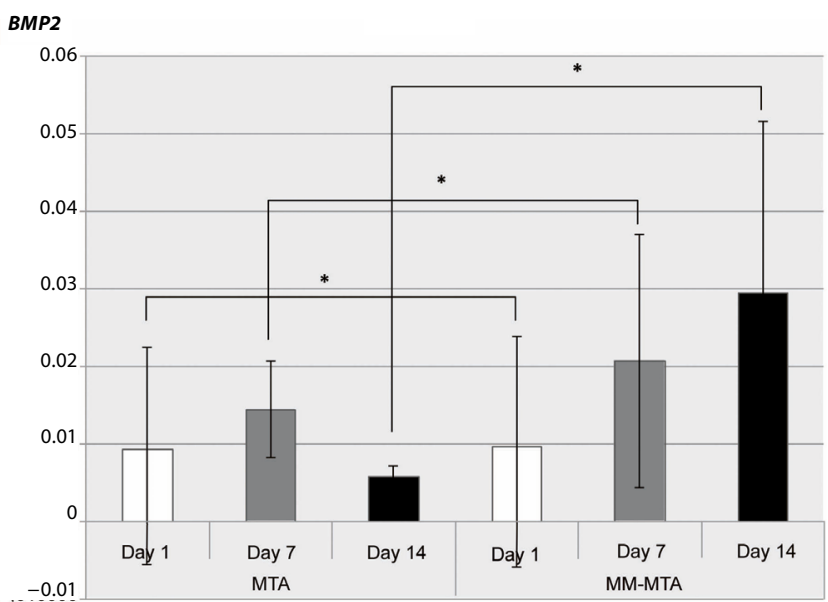

Fig. 3. The effects of MTA and MM-MTA on BMP2 mRNA levels in HDPCs were determined by semi-quantitative RT-PCR at different time points (day 1,7 and 14). Significant differences between test materials are indicated by asterisk and $s\left({ }^{*} p<0.05\right)$

MTA - mineral trioxide aggregate; MM-MTA - Micro Mega MTA; HDPCs - human dental pulp cells; BMP2 - bone morphogenetic protein 2; RT-PCR - real-time polymerase chain reaction.
ALPL

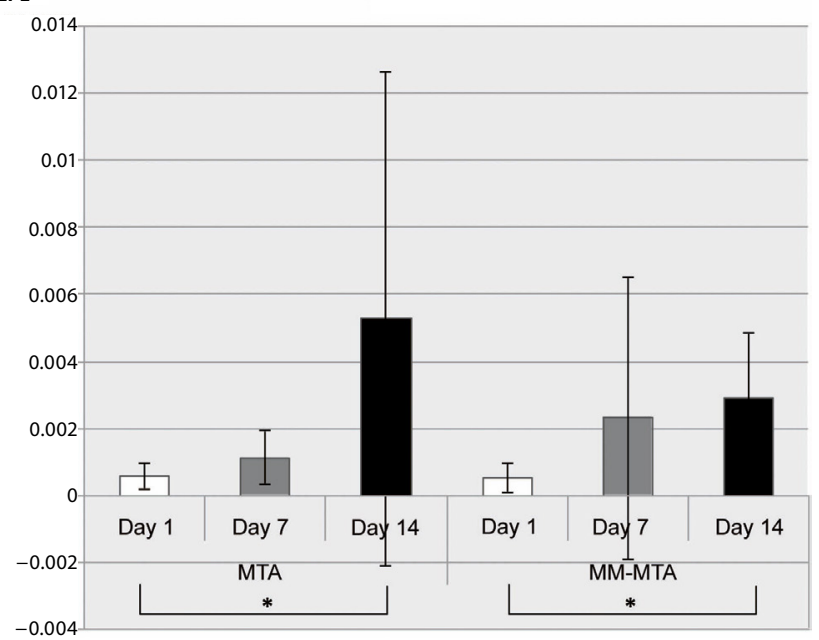

Fig. 4. The effects of MTA and MM-MTA on ALPL mRNA levels in HDPCs were determined by semi-quantitative RT-PCR at different time points (day 1, 7 and 14). Significant differences between test materials are indicated by asterisks (* $p<0.05)$

MTA - mineral trioxide aggregate; MM-MTA - Micro Mega MTA; HDPCs - human dental pulp cells; ALPL - alkaline phosphatase liver/bone/ kidney; RT-PCR - real-time polymerase chain reaction.

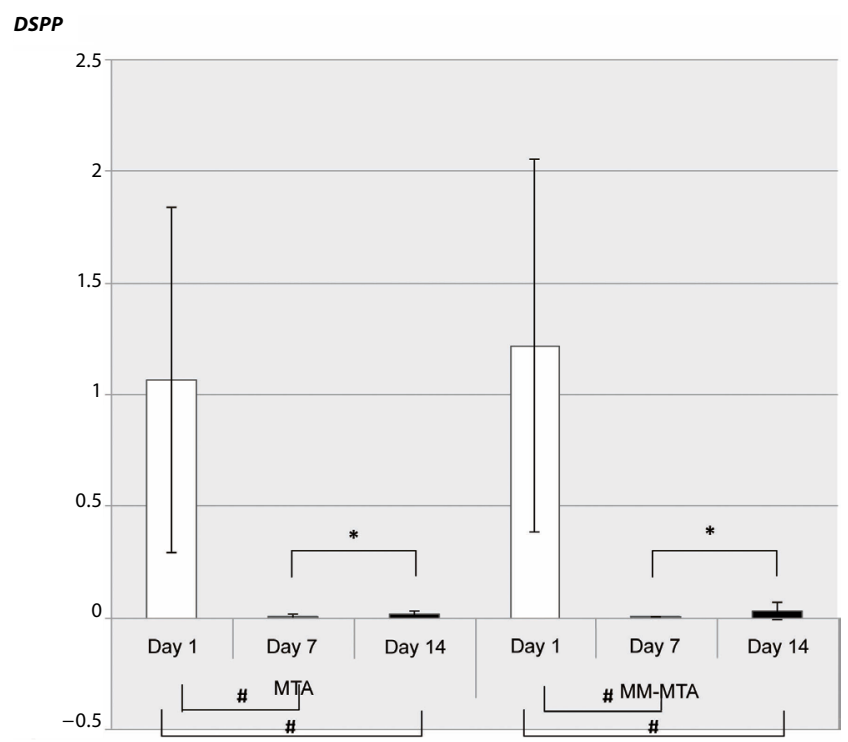

Fig. 5. The effects of MTA and MM-MTA on DSPP mRNA levels in HDPCs were determined by semi-quantitative RT-PCR at different time points (day 1, 7 and 14). Significant differences between test materials are indicated by asterisks ( $\left.{ }^{*} p<0.05\right)$ and number sign $(\# p<0.01)$

MTA - mineral trioxide aggregate; MM-MTA - Micro Mega MTA; HDPCs - human dental pulp cells; DSPP - dentin sialophosphoprotein; RT-PCR - real-time polymerase chain reaction.

\section{Discussion}

Dentinogenesis is the dentin formation process in which odontoblasts are responsible for the organic matrix synthesis and posterior mineral crystal deposition in this matrix. This pattern of formation is similar to that of bone, another mineralized connective tissue. ${ }^{23}$ For both mineralized tissues, it is of fundamental importance to understand how 
RUNX2

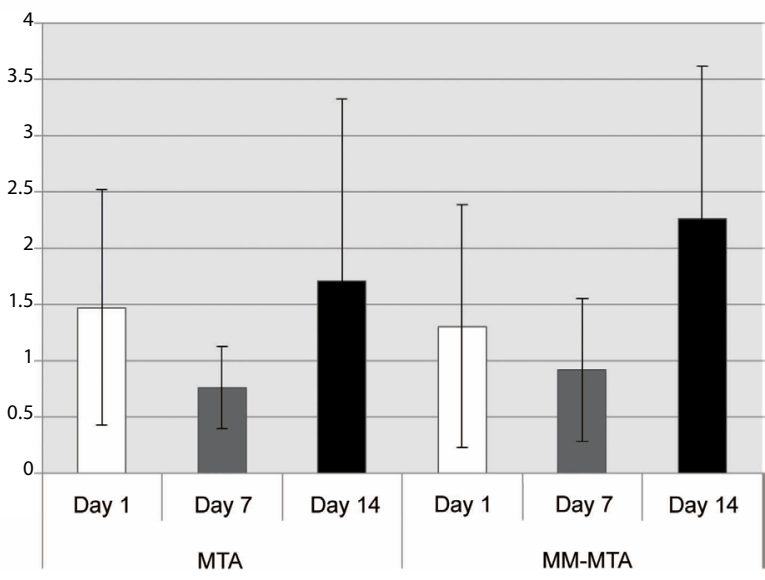

Fig. 6. The effects of MTA and MM-MTA on RUNX2 mRNA levels in HDPCs were determined by semi-quantitative RT-PCR at different time points (day 1, 7 and 14). There were no significant differences ( $p>0.05$ )

MTA - mineral trioxide aggregate; MM-MTA - Micro Mega MTA; HDPCs - human dental pulp cells; RUNX2 - runt-related transcription factor 2; RT-PCR - real-time polymerase chain reaction.

DLX3

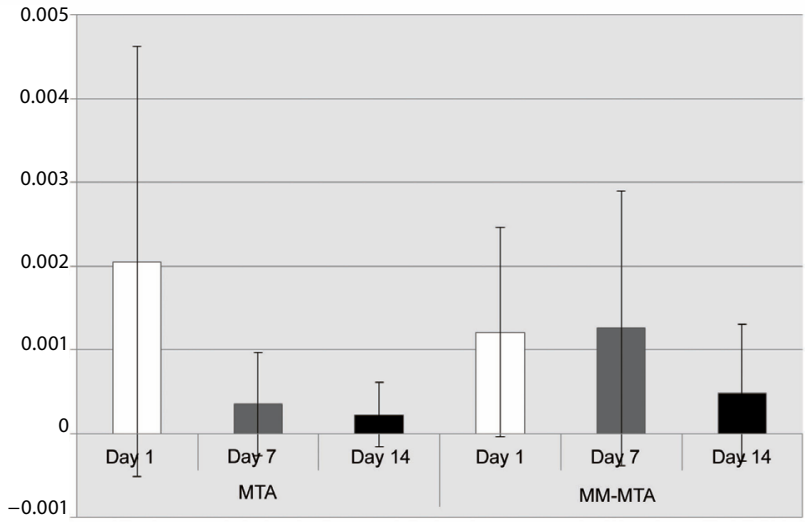

Fig. 7. The effects of MTA and MM-MTA on DLX3 mRNA levels in HDPCs were determined by semi-quantitative RT-PCR at different time points (day 1, 7 and 14). There were no significant differences ( $p>0.05$ )

MTA - mineral trioxide aggregate; MM-MTA - Micro Mega MTA; HDPCs - human dental pulp cells; DLX3 - distal-less homeobox 3; RT-PCR - real-time polymerase chain reaction.

the different biomaterials are capable of promoting odontogenic differentiation.

In this study, the effect of MTA and MM-MTA on odontogenic differentiation of HDPCs is evaluated by measuring the mRNA levels of various differentiation markers genes and $A L P$ activity. One of these specific markers is $D S P P$, which is believed to play a regulatory role in the mineralization of reparative dentin; it also serves as a specific marker for the odontoblastic phenotype. ${ }^{24}$ Bone morphogenetic proteins are a group of cytokines that play an important role in stem cells' activity, adjusting the proliferation and differentiation of cells (e.g., osteoblast), and bone formation. ${ }^{25}$ The up-regulation of $A L P L$ (also known as tissue-nonspecific) has been associated with the onset of osteogenesis in vitro and its transcription can be up-regulated by BMPs. ${ }^{26}$ Runt-related transcription factor 2 is a transcription factor that plays an essential role in bone and tooth development. The up-regulation of RUNX2 in early odontoblasts followed by the downregulation in differentiated and functional odontoblasts suggests that it is important for RUNX2 to maintain the developmental stage-specific expression during odontogenic differentiation. ${ }^{27}$ Homeodomain gene $D L X 3$ has been recently demonstrated as a potent regulator for proliferation and odontoblastic differentiation of HDPCs. ${ }^{28}$ Alkaline phosphatase activity is frequently used for the evaluation of biologic mineralization. ${ }^{29}$ This enzyme is crucial for the initiation (but not for the progression/maintenance) of the matrix mineralization process. ${ }^{30}$

In the present study, we aimed to reflect the clinical conditions of direct pulp capping in which the contact between pulp cells and biomaterials occurred indirectly through blood clots and physiologic fluids, which might not accurately model clinical setting. Seo et al. stated that the use of an interposed membrane only allows for the assessment of the effect of the diffusible components of MTA. ${ }^{12}$ The results of the present study showed that ALP activity, calcium levels and mRNA expression levels of the dental pulp cells after treatment with elutes of MTA and MM-MTA were not significantly different compared with those of the untreated cells in the negative control group. This situation may be attributed to the permeable transwell inserts, which could act as a barrier and possibly decrease activation of the dental pulp cells. ${ }^{31}$ Developing a model that would allow studying the effect of direct interaction between materials and dental pulp cells would be important for future studies.

In previous studies, MM-MTA has demonstrated similar characteristics to MTA when considering its ability to form a dentinal bridge, biocompatibility, osteo-/odontogenic differentiation capability, inflammatory response, and angiogenic potential. ${ }^{19-21}$ The results of the present study agree with previous descriptions of these biomaterials in terms of odontogenic activity. ${ }^{21}$ Our results were also consistent with the study carried out by Chang et al., who reported similar $A L P$ activity and up-regulation of odontoblastic markers such as ALP and DSPP between MTA and MM-MTA at 7 and 14 days. ${ }^{32}$ In the present study, DSPP gene was significantly down-regulated after day 1 and again significantly up-regulated after day 7 by both biomaterials. This could be attributed to a 14-day culture period, which might be the reason for unexpected differentiation results for both biomaterials. ${ }^{33}$ Higher gene expression levels might be obtained in a longer period.

Extracellular proteins, particularly family of the transforming growth factor (TGF) proteins, including BMPs, have been explained in stem cell research as potent molecules to induce odontogenic differentiation. Micro-Mega MTA exhibited higher BMP2 expression than MTA at all time periods of the present study. Despite similar calcium levels, the different effects of MM-MTA and MTA 
on $B M P 2$ expression may be related to the differences in the speed of ion release in 2 biomaterials during the culture period. A study by Setbon et al., which, which investigated the composition of different tricalcium silicate cements, revealed that MM-MTA possessed a higher concentration of magnesium and sodium than MTA. ${ }^{34}$ It has been demonstrated that these elements may represent an interest in terms of stimulation of osteodifferentiation. ${ }^{35}$ Further pharmacokinetic studies on MM-MTA and MTA are, therefore, required to characterize and compare the ions released from these 2 biomaterials.

Expression patterns of homeobox genes of $D L X$ family have been investigated during early stages of mouse odontogenesis. From that data, $D L X$ genes have been proposed to contribute to odontogenic patterning. ${ }^{36} \mathrm{It}$ is also shown that $D L X 3$ supports the osteogenic differentiation in dental follicle cells via a $B M P 2$ positive feedback loop. ${ }^{37}$ Moreover, Li et al. stated that $D L X 3$ expression progressively increased during odontoblast differentiation. ${ }^{28}$ In contrast with those studies, the present study showed no significant up-regulation of $D L X 3$ marker at all time periods of the study. Further studies are required to reveal more details about the relationship between $D L X$ transcription factors and the regulation of the odontogenic differentiation. These studies will also be available to disclose new information about the regulation of the $B M P 2 / D L X 3$ pathway.

\section{Conclusions}

Within the parameters of this study, MM-MTA exhibited higher $B M P 2$ expression than MTA at all time periods of the present study. Overall, MTA and MM-MTA showed similar osteo-/odontogenic-like phenotype differentiation of HDPCs with the mechanisms of up-regulation of the majority of osteo-/dentinogenesis-related genes. In this respect, our results suggest that MM-MTA is a potential alternative to MTA for use as an effective pulp capping material. More clinical studies are needed to assess if the expressions of these markers are clinically relevant.

\section{References}

1. Kuratate $M$, Yoshiba K, Shigetani Y, et al. Immunohistochemical analysis of nestin, osteopontin, and proliferating cells in the reparative process of exposed dental pulp capped with mineral trioxide aggregate. J Endod. 2008;34(8):970-974.

2. Nair PNR, Duncan HF, Pitt Ford TR, et al. Histological, ultrastructural and quantitative investigations on the response of healthy human pulps to experimental capping with mineral trioxide aggregate: A randomized controlled trial. Int Endod J. 2008;41(2):128-150.

3. Regan JD, Gutmann JL, Witherspoon DE. Comparison of Diaket and MTA when used as root-end filling materials to support regeneration of the periradicular tissues. Int Endod J. 2002;35(10):840-847.

4. Torabinejad M, Pitt Ford TR, Mckendry DJ, et al. Histologic assessment of mineral trioxide aggregate as a root-end filling in monkeys. J Endod. 1997;23(4):225-228.

5. Koh ET, Torabinejad M, Pitt Ford TR, et al. Mineral trioxide aggregate stimulates a biological response in human osteoblasts. $J$ Biomed Mater Res. 1997;37(3):432-439.
6. Mitchell PJ, Pitt Ford TR, Torabinejad M, et al. Osteoblast biocompatibility of mineral trioxide aggregate. Biomaterials. 1999;20(2):167-173.

7. Balto HA. Attachment and morphological behavior of human periodontal ligament fibroblasts to mineral trioxide aggregate: A scanning electron microscope study. J Endod. 2004;30(1):25-29.

8. Bonson S, Jeansonne BG, Lallier TE. Root-end filling materials alter fibroblast differentiation. J Dent Res. 2004;83(5):408-413.

9. Gandolfi MG, Ciapetti G, Taddei P, et al. Apatite formation on bioactive calcium-silicate cements for dentistry affects surface topography and human marrow stromal cells proliferation. Dent Mater. 2010;26(10): 974-992.

10. Gandolfi MG, Shah SN, Feng R, et al. Biomimetic calcium-silicate cements support differentiation of human orofacial mesenchymal stem cells. J Endod. 2011;37(8):1102-1108.

11. Min KS, Park HJ, Lee SK, et al. Effect of mineral trioxide aggregate on dentin bridge formation and expression of dentin sialoprotein and heme oxygenase-1 in human dental pulp. $J$ Endod. 2008;34(6): 666-670.

12. Seo MS, Hwang KG, Lee J, et al. The effect of mineral trioxide aggregate on odontogenic differentiation in dental pulp stem cells. J Endod. 2013;39(2):242-248.

13. Ber BS, Hatton JF, Stewart GP. Chemical modification of ProRoot MTA to improve handling characteristics and decrease setting time. J Endod. 2007;33(10):1231-1234.

14. Johnson BR. Considerations in the selection of a root-end filling material. Oral Surg Oral Med Oral Pathol Oral Radiol Endod. 1999;87(4): 398-404.

15. Kum KY, Kim EC, Yoo YJ, et al. Trace metal contents of three tricalcium silicate materials: MTA Angelus, Micro Mega MTA and Bioaggregate. Int Endod J. 2014;47:704-710.

16. Khalil I, Naaman A, Camilleri J. Investigation of a novel mechanically mixed mineral trioxide aggregate (MM-MTA $\left.{ }^{T M}\right)$. Int Endod J. 2015;48(8): 757-767.

17. Tanalp J, Karapınar-Kazandağ $M$, Dölekoğlu S, et al. Comparison of the radiopacities of different root-end filling and repair materials. The Scientific World Journal. 2013;23:594950. doi: 10.1155/2013/594950

18. Celik D, Er K, Serper A, et al. Push-out bond strength of three calcium silicate cements to root canal dentine after two different irrigation regimes. Clin Oral Investig. 2014;18:1141-1146.

19. Khalil IT, Sarkis T, Naaman A. MM-MTA for direct pulp capping: A histologic comparison with ProRoot MTA in rat molars. J Contemp Dent Pract. 2013;14(6):1019-1023.

20. Margunato S, Taşı PN, Aydın S, et al. In vitro evaluation of ProRoot MTA, Biodentine, and MM-MTA on human alveolar bone marrow stem cells in terms of biocompatibility and mineralization. J Endod. 2015;41(10):1646-1652.

21. Chang SW, Bae WJ, Yi JK, et al. Odontoblastic differentiation, inflammatory response, and angiogenic potential of 4 calcium silicatebased cements: Micromega MTA, ProRoot MTA, RetroMTA, and experimental calcium silicate cement. J Endod. 2015;41(9):1524-1529.

22. Livak KJ, Schmittgen TD. Analysis of relative gene expression data using real-time quantitative PCR and the 2(-Delta Delta $C(T)$ ) method. Methods. 2001;25(4):402-408.

23. Linde A. Dentin mineralization and role of odontoblasts in calcium transport. Connect Tissue Res. 1995;33(1-3):163-170.

24. Iohara K, Nakashima M, Ito M, et al. Dentin regeneration by dental pulp stem cell therapy with recombinant human bone morphogenetic protein 2. J Dent Res. 2004;83(8):590-595.

25. Kim JY, Kim MR, Kim SJ. Modulation of osteoblastic/odontoblastic differentiation of adult mesenchymal stem cells through gene introduction: A brief review. J Korean Assoc Oral Maxillofac Surg. 2013;39(2): 55-62.

26. Tylzanowski P, Verschueren $K$, Huylebroeck D, et al. Smad-interacting protein 1 is a repressor of liver/bone/kidney alkaline phosphatase transcription in bone morphogenetic protein-induced osteogenic differentiation of C2C12 cells. J Biol Chem. 2001;276:40001-40007.

27. Yang F, Xu N, Li D, et al. A feedback loop between RUNX2 and the E3 ligase SMURF1 in regulation of differentiation of human dental pulp stem cells. J Endod. 2014;40:1579-1586.

28. Li X, Yang G, Fan M. Effects of homeobox gene distal-less 3 on proliferation and odontoblastic differentiation of human dental pulp cells. J Endod. 2012;38(11):1504-1510. 
29. Wöltgens JH, Lyaruu DM, Bronckers AL, et al. Biomineralization during early stages of the developing tooth in vitro with special reference to secretory stage of amelogenesis. Int J Dev Biol. 1995;39: 203-212.

30. Bellows CG, Aubin JE, Heersche JN. Initiation and progression of mineralization of bone nodules formed in vitro: The role of alkaline phosphatase and organic phosphate. Bone Miner. 1991;14(1):27-40.

31. Paranjpe A, Smoot $\mathrm{T}$, Zhang $\mathrm{H}$, et al. Direct contact with mineral trioxide aggregate activates and differentiates human dental pulp cells. J Endod. 2011;37(12):1691-1695.

32. Chang SW, Lee SY, Kum KY, et al. Effects of ProRoot MTA, Bioaggregate, and Micromega MTA on odontoblastic differentiation in human dental pulp cells. J Endod. 2014;40(1):113-118.
33. Güven EP, Taşli PN, Yalvac ME, et al. In vitro comparison of induction capacity and biomineralization ability of mineral trioxide aggregate and a bioceramic root canal sealer. Int Endod J. 2013;46(12):1173-1182.

34. Setbon HM, Devaux J, Iserentant A, et al. Influence of composition on setting kinetics of new injectable and/or fast setting tricalcium silicate cements. Dent Mater. 2014;30(12):1291-1303.

35. Park KD, Lee BA, Piao XH, et al. Effect of magnesium and calcium phosphate coatings on osteoblastic responses to the titanium surface. J Adv Prosthodont. 2013;5:402-408.

36. Thomas B, Sharpe P. Patterning of the murine dentition by homeobox genes. Eur J Oral Sci. 1998;106:48-54.

37. Viale-Bouroncle $\mathrm{S}$, Felthaus $\mathrm{O}, \mathrm{Schmalz} \mathrm{G}$, et al. The transcription factor $D L X 3$ regulates the osteogenic differentiation of human dental follicle precursor cells. Stem Cells Dev. 2012;21(11):1936-1947. 